\title{
MOÇAMBIQUE: DIVERSIDADE CULTURAL E LINGUÍSTICA
}

\section{MARIA INÊS FRANCISCA CIRÍACO}

Doutoranda em Letras pela Universidade Presbiteriana Mackenzie (UPM), São Paulo, SP, Brasil. E-mail: minesciriaco@gmail.com

\section{Resumo}

Esse texto, ainda que breve, nos permitirá expandir o entendimento acerca da tessitura multicultural e multilinguística de Moçambique, bem como suas implicações na estruturação da sociedade e seus reflexos na contemporaneidade. Assim sendo, o presente artigo tem por objetivo apresentar aspectos culturais e linguísticos de Moçambique, com o intuito de melhor compreender o processo de inserção do país no denominado espaço lusófono. Desse modo, voltamos nosso olhar para os mais de quatro séculos e meio da presença portuguesa na África e, especificamente, para Moçambique, país dotado de imensa riqueza cultural e linguística, mas, também arraigado às tradições ancestrais. Para tanto, situamos nossas reflexões no âmbito dos Estudos Lusófonos e tomamos como referencial teórico as linguistas Regina Helena Pires de Brito e Neusa Maria Oliveira Barbosa Bastos $(2006 ; 2008 ; 2010 ; 2013)$. O artigo também se baseia no pesquisador Eduardo Lourenço (2001), cujas ideias permitem que tenhamos uma visão maior sobre questões culturais e linguísticas decorrentes da colonização portuguesa na África. 


\section{Palavras-chave}

Moçambique. Cultura. Língua portuguesa.

O presente artigo tem por objetivo apresentar aspectos culturais e linguísticos de Moçambique, com o intuito de melhor compreender o processo de inserção do país no denominado espaço lusófono. Desse modo, voltamos nosso olhar para os mais de quatro séculos e meio da presença portuguesa na África, mais especificamente para Moçambique, país dotado de imensa riqueza cultural e linguística, mas, também, arraigado às tradições ancestrais.

A história cultural e linguística na África é herança da ocupação e da dominação dos territórios africanos por diferentes povos desde a antiguidade clássica, do século X a.C. ao XIV d.C., resultando nessa multiplicidade de culturas, línguas e tradições africanas que, hoje, tanto nos fascina quanto nos instiga à observação.

No caso dos espaços de presença portuguesa, a cultura europeia e a língua portuguesa impostas pelos colonizadores integraram-se à cultura africana, ao lado das inúmeras línguas locais, redesenhando, então, um novo quadro social, político, linguístico e cultural na África portuguesa, ou seja: nos espaços da lusofonia. Nessa direção, vale assinalar que,

nas universidades brasileiras, um número considerável de pesquisas têm sido realizadas acerca do conceito de lusofonia, das relações entre história e literatura, da multiculturalidade, da diversidade cultural e das variedades da língua portuguesa em relação às línguas nacionais de cada um (PALOPs), o que se reflete na crescente publicação de artigos científicos, no aumento do número de alunos de iniciação científica e de pós-graduação direcionados para o universo africano e na realização de encontros científicos de temática especifica dos países africanos de expressão oficial em língua portuguesa (BASTOS \& BRITO, 2013, p. 121).

Localizado na Costa oriental da África, Moçambique limita-se ao norte com a Tanzânia, a noroeste com o Malauí, a oeste com a Zâmbia e o Zimbábue, a sudoeste com a África do Sul e Suazilândia, sendo banhado a leste pelo oceano Índico. A capital é Maputo (antiga Lourenço Marques), principal cidade do país.

O país é dotado de multiplicidade cultural, étnica e linguística, legado dos primeiros habitantes dessas terras, ancestrais dos povos khoisan (ou bosquí- 
manes) e, séculos mais tarde, pelos bantu, povos falantes da língua bantu, que migraram do Norte por meio do vale do Rio Zambeze, avançando para os planaltos e áreas costeiras - os bantu ocupam quase a totalidade da África a sul do Sahara. Esses povos eram exímios agricultores, ferreiros, oleiros e tecelões; a estrutura familiar era simples, baseada nas linhagens, em que se reconheciam a figura de um chefe - característica que ainda hoje é mantida em várias regiões do país - e dos invasores que, paulatinamente, ocuparam essas terras e perduraram durante séculos de dominação e imposição das línguas, tradições e costumes.

Por sua localização estratégica, às margens do Oceano Índico, a Ilha de Moçambique tornou-se o principal porto para as embarcações que chegavam e partiam rumo à Ásia, incrementando, também, o comércio local primeiramente com os árabes e, posteriormente, com os indonésios, indianos e chineses, então, no século XVI, com os portugueses. Esse caldeamento entre a população local, pertencente ao grande grupo dos bantu e os dominadores resultou numa intensa movimentação comercial e geográfica, gerando novas comunidades, inúmeras etnias, além dos indianos e, uma grande diversidade cultural e linguística, que se distingue entre os dois lados do país. Todas essas populações estão divididas de norte a sul de Moçambique, em onze províncias.

$\mathrm{Na}$ cultura moçambicana destacam-se as artes plásticas (escultura e pintura, inclusive em tecido - técnica batik), a dança, a música, a literatura e a presença enraizada das tradições familiares e religiosas dos antepassados. Nas artes plásticas, vale ressaltar os exímios escultores Macondes, conhecidos por esculpirem no "pau preto “ (o ébano), embora o artesanato em geral seja bastante representativo em Moçambique.

$\mathrm{Na}$ pintura, existem grandes artistas que superaram barreiras e, desde o início do século XX, retratam em tela suas experiências de luta e de vida nas diversas regiões de Moçambique. Entre eles, têm reconhecimento internacional as obras de Malangatana Valente Ngwenya (1936-2011), Bertina Lopes (1924-2012), Shikhani (1934-2010), Alberto Chissano (1935-1994) e muitos outros. Por fim, na produção têxtil, outra tradição Moçambicana de fama internacional, destacam-se as coloridas Capulanas, de origem Tsonga, ${ }^{1}$ um dos símbolos da identidade feminina moçambicana, e os tecidos pintados com a técnica Batik. ${ }^{2}$

1 Tsonga: povos habitantes do sul de Moçambique, tanto na região de Gaza quanto de Maputo.

2 Batik: técnica de pintura em tecido. 
Para as populações moçambicanas, dançar e cantar são parte da essência humana; é uma forma de celebrar a vida e a morte. Todas as regiões têm as suas danças específicas, representações típicas das tradições, principalmente religiosas de cada etnia. São danças que celebram os rituais de iniciação, rituais de passagem, rituais de celebração das colheitas, de celebração dos casamentos e da morte e muitas outras, que nos dias atuais acontecem normalmente nas regiões rurais, sempre acompanhadas por músicos e instrumentistas. Os tambores são os instrumentos mais usados no acompanhamento dessas danças. No interior do país, encontram-se pequenos grupos musicais, que procuram manter vivas as tradições folclóricas. Nas cidades, embora a música acompanhe os ritmos atuais do ocidente, os músicos procuram aliar modernidade às tradições, onde buscam suas influências e criam uma nova música moçambicana. O principal ritmo musical em Moçambique é a marrabenta ${ }^{3}$, com características folclóricas e de outros ritmos moçambicanos como a magika, ximgobela e $x u k u t a^{4}$. Outro aspecto cultural é a literatura, a qual segundo Devi e Seabra (1971, p. 113): “[...] não surge espontaneamente, sem uma tradição, e que esta não pode improvisar-se. Tem de brotar naturalmente em uma superestrutura própria, ser elaborada num processo íntimo e prolongado de civilização “.A produção escrita moçambicana surgiu durante o período colonial com as grandes navegações e, em 1854, com a instalação da imprensa, as primeiras publicações. Já as obras de maior relevância surgiram no século XX, destacando-se os jornais $O$ Africano (1909) e o Brado Africano (1918), ambos voltados para a população local. Escreviam sobre temáticas de interesses particulares e locais, e o mais significativo eram publicações bilíngues, com textos em português e em língua ronga, ressaltando sempre a questão do assimilado, o que não os deixa esquecer-se da condição de colonizado, daquele ser em situação fronteiriça, entre dois mundos. Em decorrência dos muitos séculos da dominação portuguesa na África, deu-se a imposição da língua e da cultura do colonizador num amplo processo de assimilação. Dessa relação, observamos o surgimento da imprensa, em que escritores africanos produziam textos sob a perspectiva da escrita europeia. No entanto, se, por um lado, essas narrativas fazem

3 “A marrabenta surgiu nas décadas de 1930 e 1940. É um ritmo urbano de origem do sul do país e seu nome provém de rebenta, associada a dançar em excesso “. Disponível em: <http://www.buala.org/pt/ palcos?page=7>. Acesso em: 06 fev. 2017.

4 Ritmos musicais de Moçambique que foram se transformando até se tornarem a marrabenta.

97 
pouca ou nenhuma menção às línguas nacionais, por outro lado apresentam muitas referências a autores franceses, latinos e europeus, exaltando-os como modelos a serem seguidos; é o momento em que, segundo Ferreira (s.d., p. 33), "o escritor africano encontra-se em estado quase absoluto de alienação, incapaz de se libertar dos modelos europeus “.

Todavia, o próprio desenvolvimento da literatura africana lusófona sugere análise e reflexão críticas, desde o momento em que nacionalismo e identidade tornam-se conceitos essenciais na criação de uma literatura anticolonial (1900-1930), ideologicamente centrada na ideia de negritude, superando a alienação dos escritores, por um sentimento nacional. À medida que o escritor amadurece e reconhece a si mesmo como sujeito da própria história, começaram a surgir textos conscienciosos e com objetivos mais definidos, integrados ao meio e carregados de ideologia libertária, perpassando todo o período das lutas de libertação, até culminar com a independência nacional.

Ao longo desse processo, foram surgindo, paulatinamente, grandes escritores, preocupados não somente com o fazer poético, mas também com as questões históricas, sociais, políticas, culturais e linguísticas, que perpassam o universo africano e que refletem, diretamente, na produção literária desses sujeitos. Conforme Bastos e Brito (2013, p. 122), dentre os inúmeros autores africanos com os quais temos tido contato, quer por meio de suas obras, quer por intermédio de trabalhos acadêmicos ou da mídia em geral, é relevante, destacarmos, de Moçambique: Abel Coelho (1953- ), Eduardo White (1966-2014), José Craveirinha (1922-2003), Luis Bernardo Honwana (1942- ), Mia Couto (1955- ), Noémia de Souza (1926-2002), Paulina Chiziane (1955- ) e Ungulani Ba Ka Khosa (1957- ).Além dos autores citados, muitos outros compõem esse grupo de intelectuais que se dedicam a estudar e a compreender que a composição entre cultura, língua e a literatura passa, necessariamente, pelo reconhecimento do indivíduo e pelas relações estabelecidas nos diversos momentos da história de uma nação. Em outras palavras, para entender a dinâmica da produção literária africana de expressão em língua portuguesa, é preciso estar atento a todos os aspectos que envolvem a constituição identitária desse sujeito, escritor africano, além das fronteiras linguísticas e geográficas, possuidor de raízes e tradições únicas. Nesse sentido, Mata (2000) afirma que o que as literaturas africanas intentam propor nestes tempos pós-coloniais é que as identidades (nacionais, regionais, culturais, ideológicas, socioeconômicas, estéticas) gerar-se-ão da capacidade de aceitar as diferenças. 
Nesse cenário de transformação pós-independência, a literatura nas ex-colônias africanas se reabasteceu com as energias da libertação. Houve um florescimento da escrita em que os autores, sem nenhuma apreensão, narram suas lutas, sucessos e malogros, cantam em verso e prosa a riqueza multicultural e linguística da "terra-mãe" África e do seu povo, clamando por justiça, paz e reconhecimento. É o momento de busca pela afirmação de uma literatura que expresse valores, sentimentos, anseios e conceitos genuinamente africanos.

É nesse contexto que caminha a literatura moçambicana de expressão em língua portuguesa, detentora de características peculiares e impregnada de elementos singulares, específicos da pluralidade étnica, linguística, social, política e cultural, de que é dotado o país e que a torna única no universo da lusofonia. A II Guerra Mundial também marcou a história literária e cultural de Moçambique. A partir desse momento, muito se discutiu sobre os pontos de maior relevância durante o período de formação da literatura moçambicana.

No âmbito literário, surgiu uma produção que teve papel importante na luta pela independência e pelo reconhecimento do país e que, no período pós-independência, vem exercendo forte função histórica ao debater sobre as questões de identidade e a condição do moçambicano pós-colonial. $\mathrm{Na}$ visão de Abdala Junior (2007, p. 199), “os escritores engajados procuram voltar-se para a realidade social, para a vida de seu tempo", ou seja, aponta para a criação de uma literatura nacional, que oportunize ao homem moçambicano conscientizar-se de quem é e do que é capaz.

Com o início da Guerra de Libertação (1964-1974), instaurou-se nova fase no desenvolvimento da literatura moçambicana, que passou a ser um instrumento a mais na luta pela liberdade, diante da complexidade das relações estabelecidas em Moçambique. Com a independência, a condição literária do país também sofreu transformações, em que escritores e intelectuais traçaram novos rumos e ocorreu a dispersão de muitos deles. "Diríamos que a independência terminou com um sistema de duplicidade literária em que muitos escritores desenvolviam o seu trabalho e foi clarificando o panorama da literatura moçambicana" ${ }^{5}$ (PORTUGAL, 1999, p. 95).

5 O autor explica que a "duplicidade literária" desses escritores - fenômeno, aliás, muito significativo em Moçambique - tem a ver com a estratificação muito marcada na sociedade colonial: negros, brancos e mestiços, com as suas próprias associações e a sua produção cultural também diferente. 
A partir de 1975, instaurou-se uma nova conjuntura literária, em que o momento pós-independência marcou o início da busca por novas formas de expressão, que resultassem na descoberta de uma identidade literária moçambicana e, com essa intenção, os autores deixaram de lado a produção de aspecto mais coletivo e adotaram uma postura individual, como necessidade de relatar suas experiências sobre o período anterior e durante a nova realidade estabelecida com a independência.

Diante do desejo de uma genuína literatura moçambicana, já no final do século XX e início do século XXI, despontou a escrita de autoria feminina (marginalizada no próprio país até esse momento) com publicações de escritoras como Lília Momplé (1935- ) e Paulina Chiziane (1955- ), primeira mulher a publicar um romance em Moçambique, com repercussão internacional: Niketche: uma história de poligamia (2001).

A literatura feminina revela Moçambique sob uma perspectiva diferente da apresentada até então. É uma das formas de manifestar a inquietude das mulheres diante das questões sociais e políticas, além de discutir os conflitos identitários, a condição de submissão a que estão expostas e as relações familiares e matrimoniais, é a possibilidade de escrever a própria história. Vale salientar, que a pouca participação das mulheres na literatura moçambicana se dá pela falta de conhecimento e domínio da língua portuguesa. É, portanto, por meio de suas obras, que autores e autoras de Moçambique apresentam o que vem a ser a tão desejada moçambicanidade literária, resultado do mosaico cultural que se evidencia no país.

As diferenças culturais entre o norte e o sul de Moçambique são mais visíveis nas relações familiares, principalmente nas questões de gênero. Estudos realizados pelo Chr. Michelsen Institute (CMI) sobre gênero e pobreza em Moçambique, em relatório publicado em outubro de 2010 (CHR. MICHELSEN INSTITUTE, 2010), revelam que as diferenças entre homens e mulheres têm grande impacto social e econômico no país. As mulheres, desde os tempos tribais, sempre foram expostas a situações de vida humilhante e sob estado de submissão. As responsabilidades domésticas recaem sobre elas, o que resulta numa a carga excessiva de trabalho, além da falta de condições de saúde e precariedade da educação e da violência doméstica e abuso sexual. Estes são problemas que, desde a independência, o governo vem tentando resolver, a partir da criação de políticas que mudem tais condutas. Entretanto, sendo Moçambique um país arraigado às tradições, asso- 
ciado ao alto nível de pobreza e as relações de poder, essas ações se desenvolvem muito lentamente.

No norte de Moçambique, a estrutura familiar se mantém ligada às tradições do povo macua, associada às influências mulçumanas e portuguesas. Embora seja uma cultura patriarcal, a forma de tratamento das mulheres está ligada ao matriarcalismo, tornando mais fácil a situação das mulheres, porque estão mais ligadas às suas famílias de origem. Neste caso, as mulheres se consideram melhores tratadas pelos homens.

No sul, ainda predomina a patrilinearidade, sendo comum o lobolo, prática que consiste no pagamento de dote, dinheiro ou bens materiais, para a família da noiva, principalmente na zona rural, tornando-a propriedade do marido. Nessa região, as mulheres foram criadas para o trabalho, para a procriação e para os cuidados com a família, devendo ao marido obediência e submissão, e a poligamia, sistema considerado ilegal e que vai contra as tradições cristãs, mas é muito comum em várias localidades do sul de Moçambique. No entanto, esta situação tem se apresentado um pouco diferente na cidade de Maputo, pois a modernização e a influência da globalização aos poucos vão mudando também a mentalidade das pessoas e alterando comportamentos.

Esse contexto brevemente traçado permite perceber que a multiculturalidade - entendida como um jogo de diferenças, quando diversos elementos culturais se associam num mesmo espaço - transformou-se em traço balizador do povo moçambicano, tecendo as características peculiares da sociedade. Assim, tendo por princípio a valorização das diferenças entre gerações, classes sociais, grupos linguísticos, etnias etc., e os grandes grupos a que pertencem, numa convivência nem sempre pacífica, vai delineando a identidade (ou identidades) do povo moçambicano.

Sobre essas relações, Canclini (2013, p. XIX) chama de hibridação, definindo-a, em princípio, como "processos socioculturais nos quais estruturas ou práticas discretas, que existiam de forma separada, se combinam para gerar novas estruturas, objetos e práticas”. Em outras palavras, os processos de hibridação constituem-se como componentes fortes e desafiadores na democratização das sociedades, diante da necessidade de entendimento entre o reconhecimento das diferenças e a globalização, movimento que cada vez mais colabora para o crescimento das desigualdades e da exclusão, permitindo "reconhecer o que contém de desgarre e o que não chega a fundir-se. Uma teoria não ingênua de hibridação é inseparável de uma consciência crítica de 
seus limites, do que não se deixa, ou não quer ou não pode ser hibridado" (CANCLINI, 2013, p. XXVII).

Cientes dos processos interculturais que ocorrem na nação moçambicana, a população vive em constante conflito com as relações de pertencimento e reconhecimento no universo lusófono dos países de língua oficial portuguesa (e, no caso africano, dos PALOPs), possuidor que é de cultura singular, rica em características oriundas de povos vários (bantu, árabes, ingleses etc.), que se estabeleceram no país antes da chegada dos portugueses, cada qual com suas línguas, religiões e costumes. Assim sendo, trazemos, a seguir, a posição que adotamos com relação ao conceito de lusofonia.

A ideia de lusofonia iniciou-se com as grandes navegações portuguesas a partir do século XV, propagando, de certa forma, também sua língua e sua cultura frente aos povos conquistados. Nesse sentido, entende-se por lusofonia os espaços que têm a língua portuguesa como língua oficial de comunicação e, dessa forma, remete-se à Comunidade dos Países de Língua Portuguesa (CPLP). O termo lusofonia, em muitos desses espaços, ainda gera algum desconforto, uma vez que, segundo Brito e Bastos (2006, p. 65), haveria um peso semântico forte na palavra por questões etimológicas: "remete a lusitano, português, relativo a Portugal “. Nessa direção, esclarece Brito (2013, p. 10):

Na verdade, do ponto de vista dos povos colonizados, é difícil dissociar o passado histórico colonial do sentido que a palavra Lusofonia traz nos dicionários: no plano etimológico, o substantivo abstrato Lusofonia liga-se à "Lusitânia", província romana pertencente à Hispânia, habitada pelos Lusitanos: a forma luso, do latim lusu, remete a lusitano, português, relativo a Portugal e a forma (de origem grega) fon relaciona-se a som, voz, palavra, língua. É desta via, portanto, que se retira seu conceito mais evidente e divulgado: o de abranger os países de língua portuguesa. Numa conceituação um pouco mais alargada, costuma-se, então, aplicar o termo "lusófono" aos indivíduos que têm em comum a Língua Portuguesa e que partilham elementos culturais e históricos.

Neste sentido,

É, pois, num contexto geograficamente disperso, naturalmente multi e pluricultural, de sistemas linguísticos vários e de diferentes normas do português, que é possivel pensar/sonhar a língua e a identidade lusófonas. Assim, a lusofonia legitima-se somente quando a entendemos múltipla e quando nela distintas vozes são reconhecidas e respeitadas. (BRITO, 2013b, p. 9) 
Segundo Couto (apud HANNA; BRITO; BASTOS, 2010, p. 167), “a maior parte dos africanos amam as suas outras línguas maternas e esperavam (e ainda esperam) que esses idiomas não sejam votados ao esquecimento ou arrumados naquilo que se chama o património tradicional". Conforme explicado pelo autor, antes de ser parte da comunidade lusófona, essas nações possuíam cada qual sua identidade, dotadas de inúmeras línguas e costumes que, embora ignorados pelo colonizador, não foram esquecidos e devem ser preservados, desenvolvidos e respeitados, cada qual em suas especificidades. Nessa mesma direção, já pontuava Lourenço (2001, p. 111):

Nem como língua, nem como cultura, nem como ficção, o imaginário lusófono se nos define hoje nos tão celebrados e gastos termos camonianos de uma só alma pelo mundo em pedaços repartida. 0 imaginário lusófono tornou-se, definitivamente, o da pluralidade e da diferença e é através dessa evidência que nos cabe, ou nos cumpre, descobrir a comunidade e a confraternidade inerentes a um espaço cultural fragmentado, cuja unidade utópica, no sentido de partilha em comum, só pode existir pelo conhecimento cada vez mais sério e profundo, assumido como tal, dessa pluralidade e dessa diferença.

É nessa perspectiva que:

[...] a lusofonia deve ser compreendida como um espaço simbólico linguístico e, sobretudo, cultural no âmbito da língua portuguesa e das suas variedades lingüísticas, que, no plano geo-sociopolítico, abarca os países que adotam o português como língua materna e oficial (Portugal e Brasil) e língua oficial (Angola, Cabo Verde, Moçambique, São Tomé e Príncipe e Guiné-Bissau - que constituem os Países Africanos de Língua Oficial Portuguesa (PALOPs) - e Timor-Leste.

Entretanto, não se pode restringir a lusofonia ao que as fronteiras nacionais delimitam. Nesse modo de conceber a lusofonia, há que se considerar as muitas comunidades espalhadas pelo mundo e que constituem a chamada "diáspora lusa" e as localidades em que, se bem que nomeiem o português como língua de "uso", na verdade, ela seja minimamente (se tanto) utilizada: Macau, Goa, Ceilão, Cochim, Diu, Damão e Málaca. Além disso, a lusofonia é inconcebível sem a inclusão da Galiza (LOURENÇO, 2001). Somam-se a isso outras regiões de presença portuguesa no passado e/ou onde, relativamente, se fala português ainda hoje: na África - Annobón (Guiné Equatorial), Ziguinchor, Mombaça, Zamzibar; na Europa - Almedilha, Cedilho, A Codosera, Ferreira de Alcântara, Galiza, Olivença, Vale de Xalma (Espanha). Essa síntese do mundo lusófono - que se procura reunir na noção de lusofonia (mesmo que 
miticamente) - pretende conciliar diversidades e afinidades linguísticas e culturais com a unidade que estrutura o sistema linguístico do português (BRITO, 2010, p. 177).

É preciso considerar outro aspecto: o fato de a língua portuguesa não ser a língua materna de países como Angola e Moçambique, onde predominam línguas nacionais africanas, e por terem atravessado um difícil período histórico de dominação colonial portuguesa, muitos não se sentem "lusófonos", como explica Namburete (2006, p. 63):

Grande parte dos escritos sobre a lusofonia coloca maior ênfase na língua portuguesa, englobando apenas os que falam português e excluindo, naturalmente, aqueles que, mesmo vivendo em países ou comunidades que decretaram o português como a sua língua oficial, não falam, não lêem e muito menos escrevem na língua de Camões.

Em outras palavras, a lusofonia é vista como espaço histórico de variações linguísticas, culturais e políticas, levando em consideração que a língua portuguesa se diferencia nas diversas nações onde é empregada, dada a pluralidade linguística e cultural de cada povo, as inter-relações linguísticas (línguas nacionais, língua portuguesa e outras línguas estrangeiras) e os interesses políticos que perpassam todo o processo da lusofonia. Brito (2008, s.p.) afirma que:

A ideia da lusofonia só faz sentido se a concebermos acima das nacionalidades, muito além de qualquer percepção mítica de uma nação, ou de responsabilidade de preservação por parte de outra. Ao entender que a língua é que nos diz a cada indivíduo lusófono, é que a lusofonia pode vir a ser, de fato: não somos 200 milhões de luso falantes; somos a língua portuguesa que fala em cada um.

É, de fato, uma noção ampla e ao mesmo tempo o sonho de todos que anseiam pelo entendimento da lusofonia, não como reprodução da língua e da cultura portuguesa, mas como espaço de interação de todos os povos que, de alguma maneira, se valem do português como língua de expressão. É simplesmente ressaltar e valorizar as diferenças culturais existentes em cada espaço lusófono, e não "apagar” os valores neles contidos, já que a "ideia de lusofonia só faz sentido se a concebermos acima das nacionalidades, muito além de qual- 
quer percepção mítica de uma nação, ou de responsabilidade de preservação por parte de outra" (BRITO \& BASTOS, 2006, p. 74). Ou seja, "Se queremos dar algum sentido à galáxia lusófona, temos de vivê-la, na medida do possível, como inextricavelmente portuguesa, brasileira, angolana, moçambicana, cabo-verdiana ou são-tomense” (LOURENÇO, 2001, p. 111).

Sendo assim, ao afirmar que "[...] a lusofonia só poderá entender-se como espaço de cultura”, Martins (2006, p. 50) nos conduz à reflexão sobre o verdadeiro sentido da lusofonia, que vai além do simples fato de pensar a língua portuguesa, é desvendar a complexidade que exige o processo de construção identitária de um povo. "Encontrar significados e direções comuns, no âmbito da lusofonia, também significa reconhecer e respeitar múltiplas e distintas vozes" (BRITO; BASTOS; HANNA, 2010, p. 160), num contexto fortemente marcado por muitos séculos de dominação do europeu, pela imposição de uma língua e de uma cultura colonizadora.

Com efeito, pontua Brito (2013b, p. 11):

Uma síntese do universo lusófono - que se procura reunir numa noção (ainda que mítica) de lusofonia - pretende conciliar diversidades linguísticas e culturais com a unidade que estrutura o sistema linguístico do português. Deste modo, como referimos, uma descrição possível apresenta uma dimensão geográfica da língua portuguesa distribuída por espaços múltiplos, numa área extensa e descontínua e, que, como qualquer língua viva, se apresenta internamente caracterizada pela coexistência de várias normas e subnormas. Estas, naturalmente, divergem de maneira mais ou menos acentuada num aspecto ou noutro, numa diferenciação que, embora não comprometa a unidade do sistema, possibilita-nos reconhecer diferentes usos dentro de cada comunidade.

Para o povo moçambicano, não é tarefa fácil ser possuidor de tão diversas culturas, por isso mesmo, entendemos que não querem se despojar dos valores culturais absorvidos durante a presença e convívio com o colonizador europeu, mas, ao mesmo tempo, desejam ver respeitadas e reconhecidas suas tradições, para, então, compreender e aceitar a transformação dessas no decorrer dos tempos.

Embora seja um árduo caminho, é por meio de uma batalha multicultural, ligada historicamente ao processo de colonização europeia e a uma política assimiladora e de alheamento da cultura e das tradições dos antepassados, que o povo moçambicano anseia pelo reconhecimento dessas diferenças, 
essencial para a valorização do patrimônio histórico, cultural e linguístico de Moçambique.

\section{Mozambique: cultural and linguistic diversity}

\section{Abstract}

This brief paper will allow us to expand our understanding of the multicultural and multilingual structure of Mozambique, as well as its implications for the structuring of society and its reflections in contemporary times. Thus, this article aims to present cultural and linguistic aspects of Mozambique, in order to understand the process of insertion of the country in the so-called lusophone space. In this way, we turn our gaze to the more than four and a half centuries of Portuguese presence in Africa, and specifically to Mozambique, a country endowed with immense cultural and linguistic richness, but also rooted in ancestral traditions. Therefore, we place our reflections within the framework of the Lusophone Studies and take as theoretical reference the linguists Regina Helena Pires de Brito and Neusa Maria Oliveira Barbosa Bastos (2006; 2008; 2010; 2013). We are also based on the researcher Eduardo Lourenço (2011), whose ideas allow us to have a greater view on cultural and linguistic issues arising from Portuguese colonization in Africa.

\section{Keywords}

Mozambique. Culture. Portuguese language.

\section{REFERÊNCIAS}

ABDALA JUNIOR, B. Literatura, história e politica: literaturas de língua portuguesa no século XX. São Paulo: Ateliê Editorial, 2007.

BASTOS, N. M. O. B.; BRITO, R. H. P. de. Mia Couto e um contato lusófono Moçambique/Brasil. (p. 113-134). In: VILNET, G. (Org.). Mozambique: littératures et sociétés contemporaines. Paris: Indigo \& Côté-femmes éditions, 2013.

BRITO, R. H. P. de. Sobre o conceito de lusofonia. Seminário do Gel, v. 56, 2008, São José do Rio Preto,SP, Brasil. Disponível em:<http://www.gel.org.br/?resumo=4434-08>. Acesso: em 25 fev. 2017. 
BRITO, R. H. P. de. Temas para a compreensão do atual quadro linguístico de Timor-Leste. Ciências \& Letras, n. 48, p. 175-194, 2010.

BRITO, R. H. P. de. Sobre Lusofonia. Verbum, n. 5, p. 4-15, 2013.

BRITO, R. P. de; BASTOS, N...M. O. B. Dimensão semântica e perspectivas do real: comentários em torno do conceito de lusofonia. (p. 65-77). In: SOUZA H.; MARTINS, M. de L. (Orgs.). Comunicação e Lusofonia. Porto: Campo das Letras, 2006.

CANCLINI, N. G. Culturas híbridas: estratégias para entrar e sair da modernidade. (Tradução de Heloísa Pezza Cintrão e Ana Regina Lessa; tradução da introdução Gênese Andrade). São Paulo: EDUSP, 2013.

CHR. MICHELSEN INSTITUTE (CMI). Não fica bem que uma mulher seja chefe quando existem homens. In: Género e Pobreza no Sul de Moçambique. Inge Tvedten (CMI) Margarida Paulo (Cruzeiro do Sul) Minna Tuominen (Austral Cowi), v. 9, n. 6, R 2010: 7. Disponível em: <http:/www.cmi.no/publications/file/3780-no-fica-bem-que-uma-mulher-seja-chefe-quando.pdf>. Acesso em: 26 fev. 2017.

COUTO, M. Alocução produzida na Conferência Internacional sobre o Serviço Público de Rádio e Televisão no contexto internacional: A experiência portuguesa, no âmbito dos 50 anos da RTP. 2007. p. 164. In: HANNA. V. L. H.; BASTOS, N. B.; BRITO, R. H. P. de. Políticas de língua e lusofonia: aspectos culturais e ideológicos. p. 159-175. Anuário Internacional de Comunicação Lusófona. Lisboa, Portugal, 2010.

DEVI, S.; SEABRA, M. de. A Literatura Indo-Portuguesa. Lisboa, Portugal: Junta de Investigação do Ultramar, 1971.

FERREIRA, M. O discurso no percurso africano I (Contribuição para uma estética africana). Lisboa: Plátano, s.d.

HANNA, V. L. H.; BRITO. R. H. P. de; BASTOS, N. B. Políticas de língua e lusofonia: aspectos culturais e ideológicos. In: Anuário Internacional de Comunicação Lusófona. p. 159-175. Lisboa, Portugal, 2010.

LOURENÇO, E. A nau de Ícaro e imagem e miragem na lusofonia. São Paulo: Companhia das Letras, 2001.

MARTINS, M. de L. Lusofonia e luso-tropicalismo: equívocos e possibilidades de dois conceitos hiper-identitários. In: BASTOS, N. B. (Org.). Língua portuguesa: reflexões lusófonas. São Paulo: EDUC, 2006, p. 49-62.

MATA, I. O pós-colonial nas literaturas africanas de língua portuguesa. X Congresso Internacional da ALADAA (Associação Latino-Americana de Estudos de Ásia e África) sobre CULTURA, PODER E TECNOLOGIA: África e Ásia face à Globalização - Universidade Cândido Mendes, Rio de Janeiro - 26 a 29 de outubro de 2000. 
NAMBURETE, E.. Língua e lusofonia: a identidade dos que não falam português. In: BASTOS, N. B. (Org.). Língua portuguesa: reflexões lusófonas. São Paulo: EDUC, 2006, p. 63-74.

PORTUGAL, F. S. Entre Próspero e Caliban: literaturas africanas de língua portuguesa. Santiago de Compostela, Galiza: Edicións Laiovento, 1999.

Recebido em 17-03-2017. Aprovado em 27-03-2017. 